\title{
Fluconazole Prophylaxis in Neonates (Non-Systematic) Literature Review
}

\author{
Abdulaziz Almulhim \\ College of Pharmacy, University of Arizona, Tucson, AZ, USA \\ Email: Almulhim@email.arizona.edu
}

How to cite this paper: Almulhim, A. (2016) Fluconazole Prophylaxis in Neonates (Non-Systematic) Literature Review. Pharmacology \& Pharmacy, 7, 473-480. http://dx.doi.org/10.4236/pp.2016.712053

Received: October 19, 2016

Accepted: December 5, 2016

Published: December 8, 2016

Copyright $\odot 2016$ by author and Scientific Research Publishing Inc. This work is licensed under the Creative Commons Attribution International License (CC BY 4.0).

http://creativecommons.org/licenses/by/4.0/ (c) (i) Open Access

\begin{abstract}
Background: Nosocomial infection remains an important contributing factor for morbidity and mortality in neonates. Coagulase-negative staphylococci have emerged as the predominant pathogens of late onset sepsis. This is followed by staphylococcus aurous, gram negative bacilli, and fungi. Old studies noted that mortality due to candidemia was higher in infants weigh less than $2000 \mathrm{~g}$ after being exposed to risk factors. The prophylactic use of fluconazole for the prevention of IC in extremely low birth weight was first reported in 2001. Methods: Current guidelines from Europe and North America that refer to the treatment of fungal infections are included. Literature search was performed using Medline, Scopus and Cochrane Central Register of Controlled Trials through March, 2016. Conclusion: Mortality was not different in early studies. However, recent studies concluded that mortality was reduced in the fluconazole arms. Risk-based approach towards fluconazole prophylaxis seems to be safe and effective.
\end{abstract}

\section{Keywords}

Invasive Candidiasis, Neonates, Preterm, Fluconazole Prophylaxis, Central Venous Catheters

\section{Introduction}

Nosocomial infection remains an important contributing factor for morbidity and mortality. Neonatal sepsis is divided into two classifications: early onset and late onset sepsis. Early onset sepsis occurs within the first 72 hours of life, while late onset sepsis occurs after 72 hours of birth. The incidence of late onset sepsis is inversely related to birth weight and gestational age [1]. Coagulase-negative staphylococci have emerged as the predominant pathogens of late onset sepsis. This is followed by staphylococcus aureus, gram negative bacilli, and fungi. Different risk factors were found to predispose 
neonates to invasive candidiasis. According to published data, colonization with candida species increases the risk of candidemia (OR 5.1\% 95\% CI 1.01 - 25.6) [2]. Neonates in the NICU may be colonized with candida species after birth through two different mechanisms. First, vertical transmission from maternal flora. Second, horizontal transmission from the hands of health care workers [3]. Old studies noted that mortality due to candidemia was higher in infants weighed less than $2000 \mathrm{~g}$ after being exposed to risk factors [4]. Mechanisms that put preterm neonates at fungal infections are multifactorial that include but may not be limited to immature immune cells, use of broad-spectrum antibiotics, and frequent breeches of the skin [5]. Studies found that candida species colonizing GI tract are identical to candida species isolated from blood in patients with candidemia [6]. Haematogenous Candida meningoencephalitis (HCME) is a unique syndrome in preterm infants, where candida invades the central nervous system. This syndrome occurs in $15 \%-20 \%$ of patients with invasive candidiasis and may contribute to long-term neurodevelopmental abnormalities [7]. In addition to that, sepsis in general was found to be associated with increase neurodevelopmental impairment among survivals [6]. Candida albicans by far are the most common species colonizing GI tract and causing invasive infection followed by candida parapsilosis [3] [8]. The European Society of Medical Infectious Diseases recommends fluconazole as the drug of choice in extremely low birth weight infants in centers where the incidence of invasive candidiasis (IC) is more or equal to $2 \%$, while centers were the incidence of IC is less than $2 \%$ should be made on a case-by-case basis and embedded in a risk stratifications strategy [7]. On the contrary, the most recent guidelines from the Infectious Disease Society of America recommended initiating fluconazole prophylaxis in centers where the incidence of IC is $10 \%$ or more. The prophylactic use of fluconazole for the prevention of IC in extremely low birth weight was first reported in 2001 [5].

\section{Methods}

Current guidelines from Europe and North America that refer to the treatment of fungal infections are included. Literature search was performed using Medline, Scopus and Cochrane Central Register of Controlled Trials through March, 2016, that reported on fluconazole prophylaxis in neonates restricted to English language. The following searching strings were used [Fluconazole AND prophylaxis AND preterm AND neonates AND invasive candidiasis AND central venous catheters]. Only clinical trials and meta-analysis reported on fluconazole prophylaxis in neonates were reviewed for analysis (Figure 1).

\section{Literature Review}

Kaufman et al. conducted the first prospective study to evaluate the efficacy of fluconazole prophylaxis in preterm neonates. The birth weight at baseline was $717+/-150$ in the fluconazole group and $744+/-157$ in the placebo group. All neonates were preterm with mean gestational age of $25.5+/-1.6$ in fluconazole group and $25.7+/-2$ in placebo group. They were randomized to receive Intravenous fluconazole $3 \mathrm{mg} / \mathrm{kg}$ every 


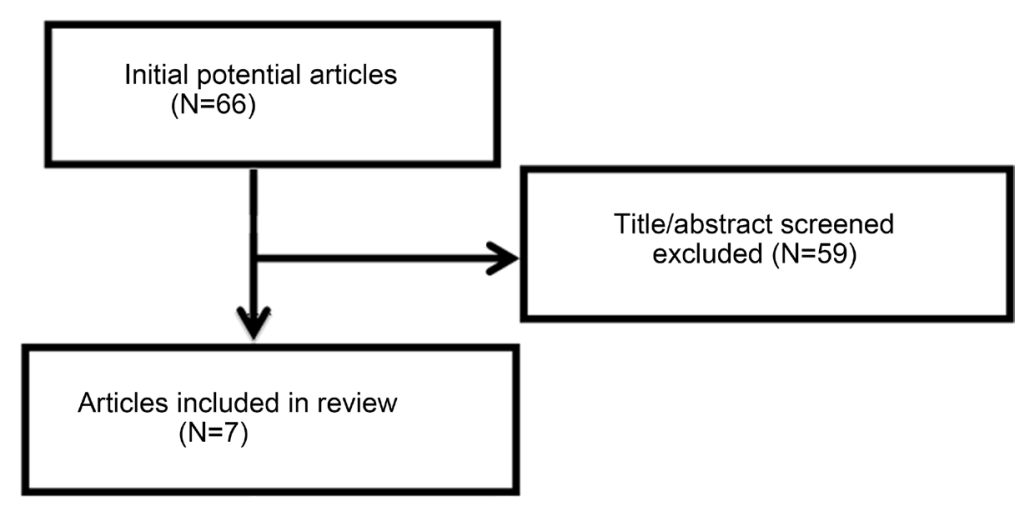

Figure 1. Studies included in review.

third day for 2 weeks, then every other day for the third and fourth week, then daily during the fifth and sixth week vs. placebo. They limited their study for the first 6 weeks of life of preterm neonates with extreme low birth weight and fluconazole was discontinued once central venous catheters are removed and neonates are extubated. Unfortunately, the incidence of IC at their facility was not stated in this study and was not specified if fluconazole will continue if other risk factors were still existed (Table 2) [5].

Rolnitsky et al. conducted a retrospective study to evaluate the efficacy of fluconazole prophylaxis in VLBW neonates. The incidence of candidiasis in their institution is low so they developed a risk based approach to initiate fluconazole in high risk neonates. They considered neonates with ELBW, gestational age of less than 28 weeks, and broad-spectrum antibiotics as major criteria and fluconazole will be discontinued once the risk factor is no longer available. Central venous catheters, endotracheal intubation, Total parenteral nutrition were considered minor criteria and a VLBW neonate will not receive fluconazole prophylaxis if he had only one risk factor (Table 2) [9].

Manzoni et al. conducted a randomized controlled trial to evaluate the prophylactic use of fluconazole in VLBW and ELBW preterm infants. The mean weight was $1065+/-280$ in the $6 \mathrm{mg} / \mathrm{kg}$ group, $1060+/-245$ in the $3 \mathrm{mg} / \mathrm{kg}$ group, and $1120+/-$ 270 in the placebo group. The mean gestational age was $28.9+/-2.3$. The primary outcome in this study was the incidence of colonization, and the incidence of IC. Colonization occurred less frequently in the 6-mg group (9.8\%) and the 3-mg group (7.7\%) than in the placebo group (29.2\%); P $<0.001$ for both comparisons. Lastly, invasive fungal infection occurred in $2.7 \%$ in the 6 -mg group and in $3.8 \%$ in the $3-\mathrm{mg}$ group, as compared with $13.2 \%$ in the placebo group; P 0.005 and P 0.02 , respectively (Table 2) [10]. Kirpal et al. conducted a randomized controlled trial to evaluate the safety, an efficacy of fluconazole prophylaxis in VLBW (Table 1) neonates. The mean weight was $1250+/-0.36$ in the fluconazole group and $1220+/-$ in the control group. The primary outcome in this study was the development of IC (Table 1). All cause mortality was considered a secondary outcome. The incidence of IC was significantly lower in the fluconazole group compared to placebo $21 \%$ versus $43.2 \%, 95 \%$ CI 0.09 $0.37, \mathrm{P} 0.04$. All cause mortality was also lower in the fluconazole group compared to 
Table 1. Abbreviations.

\begin{tabular}{cc}
\hline VLBW & Less than $1500 \mathrm{~g}$ \\
\hline ELBW & Less than $1000 \mathrm{~g}$ \\
IC & Invasive candidiasis \\
NICU & Neonatal ICU \\
TNA & Total parenteral nutrition \\
\hline
\end{tabular}

placebo, however, it didn't reach statistical significance $2.6 \%$ versus $18.9 \%>$ P 0.05 (Table 2) [11].

Ericson et al. conducted a meta-analysis for four clinical trials conducted in United States that looked at the efficacy of fluconazole in preventing IC. $72 \%$ of the enrolled neonates had a birth weight of less than $750 \mathrm{~g}$ in the placebo group and $75.58 \%$ had a birth weight of less than $1000 \mathrm{~g}$ in the fluconazole group. The primary outcome of this meta-analysis was the composite endpoint of IC and death. The OR for the composite end point was $0.48, \mathrm{P}<0.003$, and the OR for IC was $0.2, \mathrm{P}<0.001$. The incidence of death was not significantly different between placebo group and fluconazole group OR.68, P 0.14 [12].

\section{Risk Factors for Invasive Candidiasis (IC) Infection}

1) Very low birth weight and extremely low birth weight (Table 1).

2) Central venous catheter/Umbilical catheter.

3) Third generations cephalosporins and broad spectrum antibiotics.

4) Corticosteroids therapy.

5) Candida colonization.

6) Mechanical ventilation.

7) TNA.

\section{Results}

Fluconazole prophylaxis was effective in reducing the incidence of colonization and the incidence of IC in neonates with risk factors. The primary and secondary outcomes were not similar between studies (Table 2) [10] [11]. Some studies measured the difference between candida colonization with or without fluconazole prophylaxis and found significant reduction in the incidence of colonization, which was translated to reduction in the incidence of IC as well (Table 2) [5] [10] [13]. Only one trial reported the incidence of IC in their center and designed a risk-based approach for fluconazole elgibility [9]. Fluconazole was associated with transient elevation in liver transaminases that returned to baseline after discontinuation [10] [11] [13].

\section{Discussion}

Literature of the recent years supports the prophylactic use of fluconazole in ELBW and in VLBW preterm neonates with one or more risk factors (Table 1). Risk-based ap 
Table 2. Selected studies evaluated the prophylactic use of fluconazole in preterm neonates.

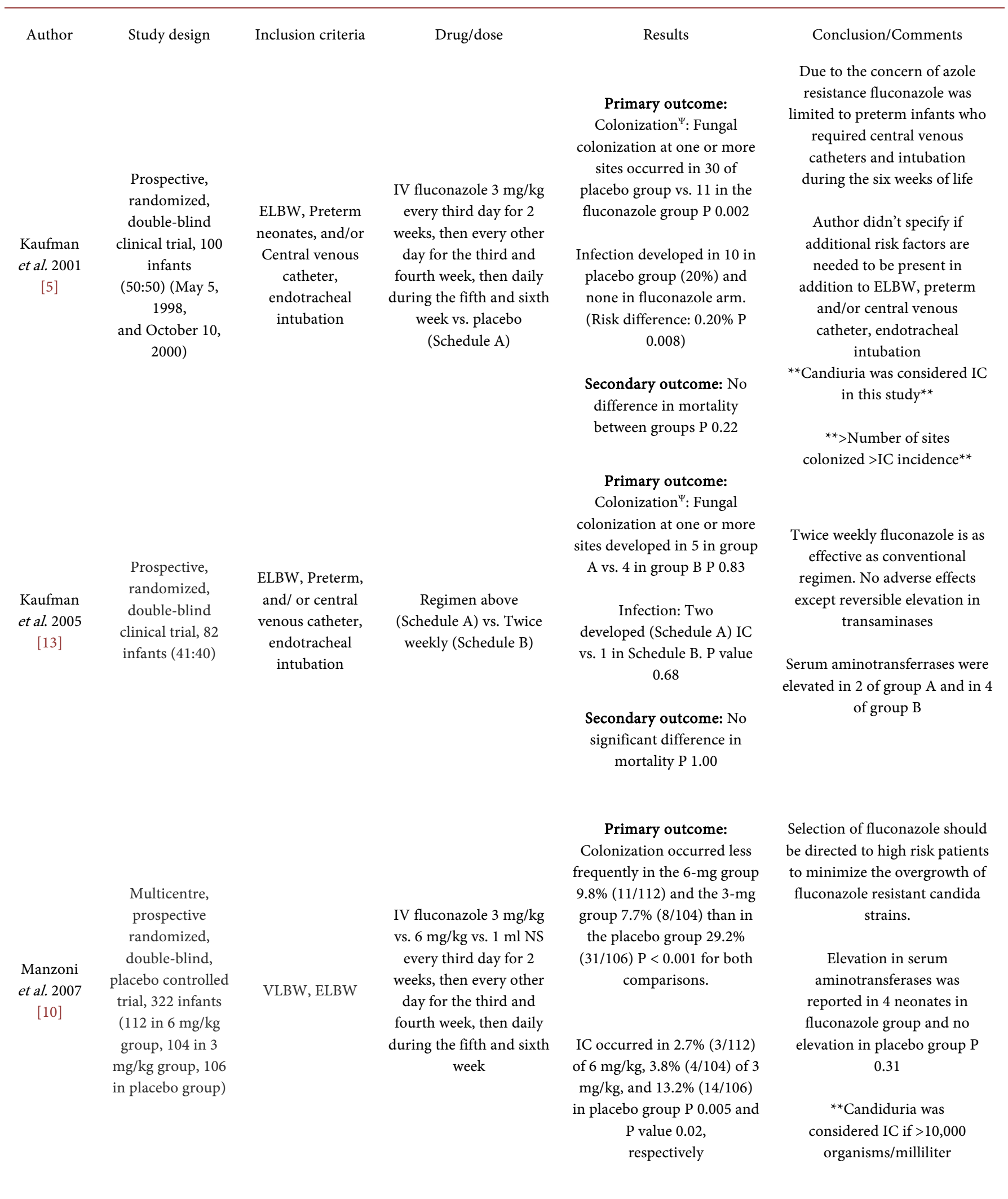




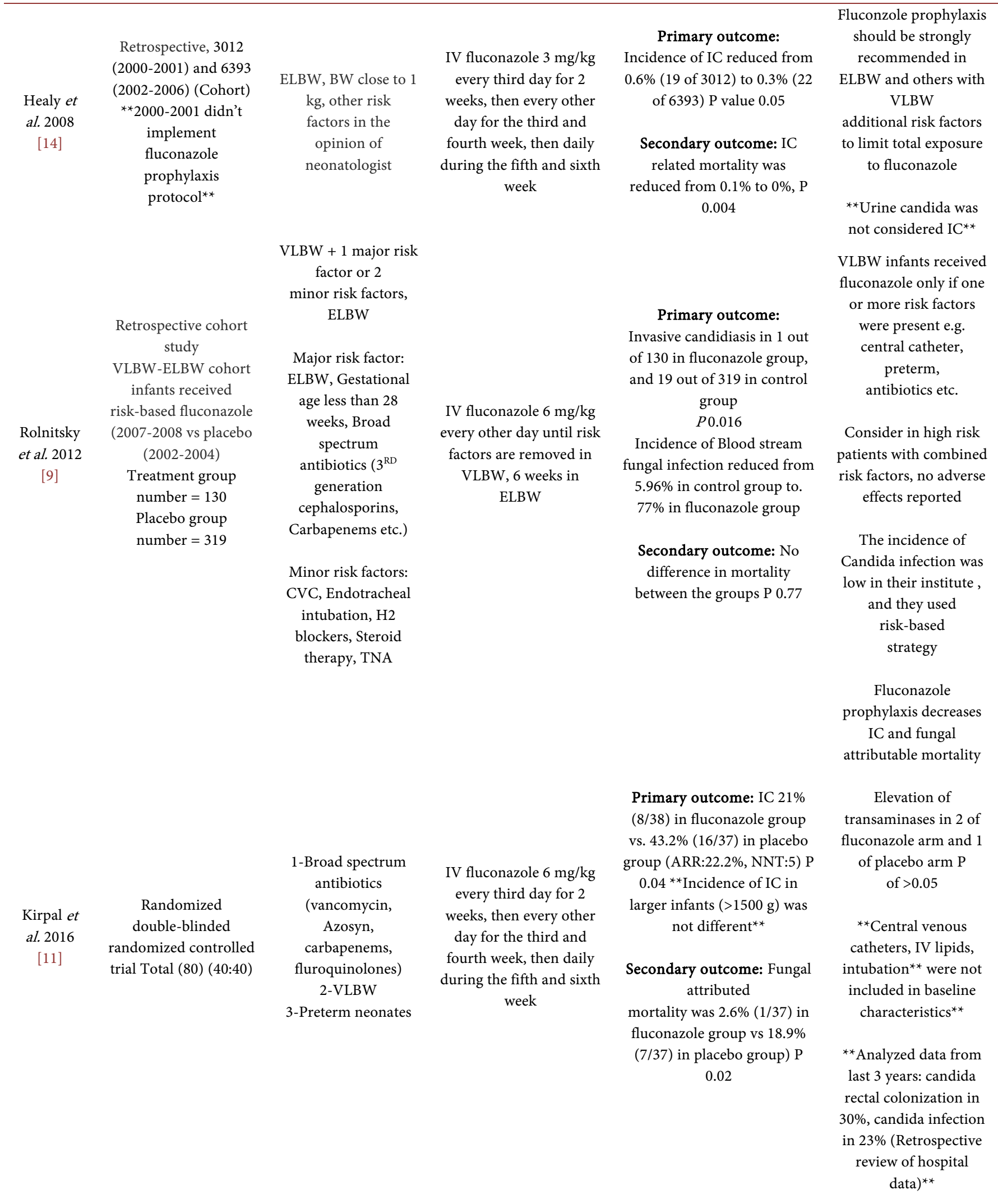


proach towards fluconazole prophylaxis seems to be safe and effective. Mortality was not different in early studies. However, recent studies concluded that mortality was reduced in the fluconazole arms [10]. In addition to that, due to the morbidity associated with systemic fungal infections, prophylaxis may be warranted in institutions where IC is at least $2 \%$ until the risk factors are no longer available. On the contrary, the most recent IDSA guidelines recommend using fluconazole prophylaxis in centers where the incidence of IC is more than $10 \%$. Neurodevelopmental complications were similar in the fluconazole group compared to placebo in patients who already developed IC. The inclusion criteria in some trials included patients with VLBW and didn't evaluate the presence of other risk factors evaluated in the previous trials [11].

Two dose regimens were used in the clinical trials and both of them showed similar outcomes:

- Fluconazole 3 - $6 \mathrm{mg} / \mathrm{kg}$ every third day for 2 weeks, then every other day for the third and fourth week, then daily during the fifth and sixth week.

- Fluconazole 3 - $6 \mathrm{mg} / \mathrm{kg}$ twice weekly for 6 weeks.

This literature review has some limitations. First, trials that investigated the safety and efficacy of oral non-absorbable antifungal agents were excluded (Figure 1). Second, research was restricted to English, which may result in missing studies investigated fluconazole prophylaxis in neonates published in different languages. Finally, larger randomized trials are needed to evaluate fluconazole safety and efficacy in Neonatal intensive care units where incidence of IC is low or unknown.

\section{Conclusion}

Fluconazole prophylaxis in preterm neonates and/or neonates with ELBW seems to be safe and effective in reducing IC. Important to remember that only IV fluconazole was tested in clinical trials for 6 weeks or as long as risk factors are available.

\section{Conflict of Interest}

Author declares that he has no conflict of interest.

\section{References}

[1] Weese-Mayer, D.E., Fondriest, D.W., Brouillette, R.T. and Shulman, S.T. (1987) Risk Factors Associated with Candidemia in the Neonatal Intensive Care Unit: A Case-Control Study. The Pediatric Infectious Disease Journal, 6, 190-196. https://doi.org/10.1097/00006454-198702000-00009

[2] Singhi, S., Rao, D.S. and Chakrabarti, A. (2008) Candida Colonization and Candidemia in a Pediatric Intensive Care Unit. Pediatric Critical Care Medicine, 9, 91-95. https://doi.org/10.1097/01.PCC.0000298643.48547.83

[3] Saiman, L., Ludington, E., Dawson, J.D., et al. (2001) Risk Factors for Candida Species Colonization of Neonatal Intensive Care Unit Patients. The Pediatric Infectious Disease Journal, 20, 1119-1124. https://doi.org/10.1097/00006454-200112000-00005

[4] Dong, Y., Speer, C.P. (2015) Late-Onset Neonatal Sepsis: Recent Developments. Archives of Disease in Childhood Fetal and Neonatal Edition, 100, F257-F263. 
https://doi.org/10.1136/archdischild-2014-306213

[5] Kaufman, D., Boyle, R., Hazen, K.C., Patrie, J.T., Robinson, M. and Donowitz, L.G. (2001) Fluconazole Prophylaxis against Fungal Colonization and Infection in Preterm Infants. The New England Journal of Medicine, 345, 1660-1666. https://doi.org/10.1056/NEJMoa010494

[6] Saiman, L., Ludington, E., Pfaller, M., et al. (2000) Risk Factors for Candidemia in Neonatal Intensive Care Unit Patients. The National Epidemiology of Mycosis Survey Study Group. The Pediatric Infectious Disease Journal, 19, 319-324. https://doi.org/10.1097/00006454-200004000-00011

[7] Hope, W.W., Castagnola, E., Groll, A.H., et al. (2012) ESCMID* Guideline for the Diagnosis and Management of Candida Diseases 2012: Prevention and Management of Invasive Infections in Neonates and Children Caused by Candida spp. Clinical Microbiology and Infection, 18, 38-52. https://doi.org/10.1111/1469-0691.12040

[8] Benjamin, D.K., Stoll, B.J., Gantz, M.G., et al. (2010) Neonatal Candidiasis: Epidemiology, Risk Factors, and Clinical Judgment. Pediatrics, 126, e865-e873.

https://doi.org/10.1542/peds.2009-3412

[9] Rolnitsky, A., Levy, I., Sirota, L., Shalit, I. and Klinger, G. (2012) Targeted Fluconazole Prophylaxis for High-Risk Very Low Birth Weight Infants. European Journal of Pediatrics, 171, 1481-1487. https://doi.org/10.1007/s00431-012-1760-2

[10] Manzoni, P., Stolfi, I., Pugni, L., et al. (2007) A Multicenter, Randomized Trial of Prophylactic Fluconazole in Preterm Neonates. The New England Journal of Medicine, 356, 24832495. https://doi.org/10.1056/NEJMoa065733

[11] Kirpal, H., Gathwala, G., Chaudhary, U. and Sharma, D. (2016) Prophylactic Fluconazole in Very Low Birth Weight Infants Admitted to Neonatal Intensive Care Unit: Randomized Controlled Trial. The Journal of Maternal-Fetal \& Neonatal Medicine, 29, 624-628. https://doi.org/10.3109/14767058.2015.1013933

[12] Ericson, J.E., Kaufman, D.A., Kicklighter, S.D., et al. (2016) Fluconazole Prophylaxis for the Prevention of Candidiasis in Premature Infants: A Meta-Analysis Using Patient-Level Data. Clinical Infectious Diseases, 63, 604-610. https://doi.org/10.1093/cid/ciw363

[13] Kaufman, D., Boyle, R., Hazen, K.C., Patrie, J.T., Robinson, M. and Grossman, L.B. (2005) Twice Weekly Fluconazole Prophylaxis for Prevention of Invasive Candida Infection in High-Risk Infants of $<1000$ Grams Birth Weight. The Journal of Pediatrics, 147, 172-179. https://doi.org/10.1016/j.jpeds.2005.03.036

[14] Healy, C.M., Campbell, J.R., Zaccaria, E. and Baker, C.J. (2008) Fluconazole Prophylaxis in Extremely Low Birth Weight Neonates Reduces Invasive Candidiasis Mortality Rates Without Emergence of Fluconazole-Resistant Candida Species. Pediatrics, 121, 703-710. https://doi.org/10.1542/peds.2007-1130 
Submit or recommend next manuscript to SCIRP and we will provide best service for you:

Accepting pre-submission inquiries through Email, Facebook, LinkedIn, Twitter, etc. A wide selection of journals (inclusive of 9 subjects, more than 200 journals)

Providing 24-hour high-quality service

User-friendly online submission system

Fair and swift peer-review system

Efficient typesetting and proofreading procedure

Display of the result of downloads and visits, as well as the number of cited articles

Maximum dissemination of your research work

Submit your manuscript at: http://papersubmission.scirp.org/

Or contact pp@scirp.org 